\title{
Short communication: Microlearning courses are effective at increasing the feelings of confidence and accuracy in the work of dairy personnel
}

\author{
A. Hesse, ${ }^{1}$ P. Ospina, ${ }^{2}$ M. Wieland, ${ }^{2}$ F. A. Leal Yepes, ${ }^{3}$ B. Nguyen, ${ }^{3}$ and W. Heuwieser ${ }^{1 *}$ \\ ${ }^{1}$ Clinic for Animal Reproduction, Faculty of Veterinary Medicine, Freie Universität Berlin, 14163 Berlin, Germany \\ ${ }^{2}$ Quality Milk Production Services, College of Veterinary Medicine, Cornell University, Ithaca, NY 14853 \\ ${ }^{3}$ Department of Population Medicine and Diagnostic Sciences, College of Veterinary Medicine, Cornell University, Ithaca, NY 14853
}

\section{ABSTRACT}

Optimization of work processes and personnel compliance becomes progressively essential to ensure high process and product quality on dairy farms with an increasingly nonfamily work force. Standard operating procedures (SOP) are important to minimize variation. In addition to having a set of protocols and SOP, regular training of employees is indispensable to reduce procedural drift. A total of 243 farm owners, employees, and veterinarians from 35 farms were invited to take 3 microlearning lessons for colostrum management and provide feedback in an embedded survey. The overall response rate was $48 \%$, and almost all participants accessed the SOP within the course (i.e., 92, 90, and $96 \%$ in the first, second, and third course, respectively). Overall, $59 \%(22 / 37)$ launched the course in their leisure time and $80 \%$ stated that they were convinced to work more accurately after having taken the course. Most employees underestimated the time spent in the course (76\%), accessed background information (89\%), or provided feedback (55\%). These observations are indicative of high engagement. Overall, $78 \%$ of employees felt more confident in correct task completion after the training.

Key words: training, e-learning, standard operating procedure, employee engagement

\section{Short Communication}

In recent decades, the US dairy industry has been experiencing a trend toward larger farms with more animals (USDA Economic Research Service, 2018). This circumstance generates new challenges on a dairy farm such as a higher number of employees per farm (Moore et al., 2016), many of whom are foreign laborers with minimal or no farming background (Reynolds,

Received October 31, 2018.

Accepted May 21, 2019.

*Corresponding author: w.heuwieser@fu-berlin.de
2013), language and communication barriers (Stup et al., 2006), and limited educational attainment (Arcury et al., 2010). Protocols ("what to do") and SOP ("how to do it") ensure high process and product quality by standardizing management practices (Barragan et al., 2016) and are essential on these farms to minimize errors (Barkema et al., 2015).

Standard operating procedures define work processes in a detailed and step-by-step way to provide the employee with clear instructions on how to perform a particular task (Amare, 2012). Variation arises when individual employees perform tasks in different ways, potentially leading to fluctuations in product quality (Stup et al., 2006).

Several studies have shown a positive effect of SOP on work performance (Barkema et al., 2015; Barragan et al., 2016), employee motivation (De Treville et al., 2005), and employee turnover (Ton and Huckman, 2008). Nevertheless, many farmers lack the expertise, time, or motivation to create SOP and protocols even though they are aware of the importance of stringent quality management (Hesse et al., 2017; Falkenberg et al., 2019). Most interesting, a recently published study showed that employers often underestimate employees' interest in learning and commitment to the success of the farm (Durst et al., 2018). The demographic change of dairy farms may be one of the causes for this discrepancy as managers face a shift in their responsibilities toward managing human resources. Furthermore, regular training of employees is indispensable to reduce procedural drift (Biagiotti, 2016). However, for many managers who started their jobs on smaller farms, this is an unfamiliar area (Reynolds, 2013).

Employee engagement and retention are important factors for dairy farms to improve turnover rates. However, the importance of these factors is not well known among dairy producers (Durst et al., 2018). Multiple studies have shown a positive effect of microlearning to impart knowledge and increase motivation of employees or undergraduate students (Gassler et al., 2004; Mohammed et al., 2018). Microlearning refers to short 
training or e-learning units that impart knowledge within small fractions with a specific goal (Mohammed et al., 2018). Cloud-based microlearning lessons provide fast and easy access to knowledge at the time of interest. The lessons can be taken independently, unsupervised, and at any time of choice. This might increase workers' motivation to accomplish the training (Mohammed et al., 2018). A review of operations management literature suggested that SOP use could result in increased self-efficacy beliefs - that is, the conviction that one is capable of achieving a given goal (Treville et al., 2005). Although training resources such as instructor-led seminars and online training are plentiful for dairy employees, science-based information on the efficacy of e-learning modules in the dairy industry is scarce. One computer-assisted training program for teaching reproductive management received positive feedback from students, veterinarians, and producers (Johnson et al., 1992). More recently, a comparison of online and hands-on training approaches for teaching cautery disbudding technique to dairy producers suggested that online training can be a useful tool for motivated producers who lack access to hands-on training (Winder et al., 2018).

The objective of this study was to determine whether an SOP embedded into an online microlearning course was accessed by dairy personnel and whether it could improve self-estimated performance of tasks related to dairy calf health. Our working hypothesis was that such microlearning courses were effective at creating feelings of confidence and accuracy in work performance.

The project was introduced at 3 different continuing education events for farmers that were conducted in Germany in the fourth quarter of 2017 and the first quarter of 2018. The audience at these events consisted of a mixed number of farm owners, herd managers, employees, and trainees. Interested farmers could provide their contact information on a handout or send the contact details of their interested employees to the project team via email. Additionally, farmers were able to provide their contact information after the first course was launched. All interested persons were then provided with the uniform resource locator (URL) and registration information. To limit the number of participants, application for course participation was closed after the second course was launched. From February to May 2018, all persons were contacted 6 times by email or WhatsApp (i.e., 1 initial email and 1 reminder email 4 $\mathrm{d}$ later for each of the 3 courses). The email contained a brief introduction to the course, the URL, and instructions on how to launch the course.

Three online microlearning courses addressing colostrum management as a fundamental basis of dairy calf health (i.e., tube feeding colostrum, bottle feeding colostrum, measuring colostrum quality) were developed with a cloud-based authoring software (Gomo Learning, Brighton, UK). The courses were accessible online and could be taken by any person who received the URL. The URL for each course was sent individually via email or WhatsApp, and the course could be accessed at any time and repeatedly. The email address of each participant had to be preregistered before participation to ensure that only persons enrolled in the learning management system were able to access the course using their preregistered email account and a password provided by the researchers. Participants could display the courses on any web-enabled device (i.e., desktop computer, smartphone, tablet computer). The first 3 screens obtained informed consent from the participants, showed a disclaimer, described the privacy policy, and explained the navigation. A typical SOP should include the purpose of the task, the equipment and materials required, and how to perform the task (Edelson and Bennett, 1998). Therefore, the course structure was based on 4 parts: (1) learning objectives; (2) the SOP, which was divided into 2 parts ("what do you need" and "how do you do it"); (3) relevant background information; and (4) a quiz for self-evaluation. The learning objectives consisted of 3 descriptions that defined what the participants should know and be able to do after completing the course. The first part of the SOP showed pictures and names of all materials needed for completing the task. The second part was a step-by-step description of the task with a title, image, and brief text beneath each image. Part 3 provided background information about each task. Eight questions per course, such as "Why 4 hours?" and "Why is quality testing of colostrum important?", allowed the participants to gain additional relevant background information relative to the SOP. This information consisted of brief texts, graphs, and images. In a concluding quiz, participants had the opportunity to take a self-evaluation consisting of 4 questions relative to the presented materials. The tube feeding course provided a detailed description of how to tube feed colostrum to newborn calves. In addition to the SOP images and text, 2 short videos showing the process of administering and pulling out the tube were available. Background information included general information about colostrum (e.g., how much colostrum should be administered, the importance of timely administration, and how to check the correct position of the tube). The bottle feeding course provided details about colostrum administration (e.g., colostrum temperature, heating frozen colostrum) and cleanliness of materials. In this course, we referred to the tube feeding course in case of the calf not voluntarily drinking $4 \mathrm{~L}$ of colostrum within $4 \mathrm{~h}$ after birth. The third course, colostrum quality, explained how to 
use a digital Brix refractometer to check colostrum quality. After reading the SOP, the participants could watch the process in a short video that was embedded at the end of the SOP. Relevant background information included details about the functioning of the refractometer, the importance of testing colostrum quality, and the importance of calibration. The concluding quizzes consisted of multiple-choice questions (1 correct out of 4 possible answers) relating to each course. If the answer selected was incorrect, the participants were able to answer again. We advised all participants that the training courses were free of charge and did not require further commitment and that they could exit the course at any point. Further, we stated that all answers were treated confidentially. Participants were able to contact the project team at any time with questions or when they experienced any problems or wanted to provide feedback. Participants did not receive an incentive. The study instrument was submitted to the human ethics committee of the Freie Universität Berlin. Only one identical microlearning approach was used for all employees, and participation was voluntary. Therefore, it was exempt by approval of the human ethics committee. However, a description of the terms and conditions of use and the privacy and data protection policies had to be provided on the first page of the course. Consent was obtained from all participants.

A 12-item survey form was embedded into each course that provided data on course perception and feedback. Two questions covered the time of course completion (i.e., whether the course was accessed during work or leisure time). One of these questions was added to the survey form when the second course was created. Further, the participants were asked to estimate the amount of time they had spent on each course. Other questions referred to the participant's position on the farm, their experience in completing the particular task, and how they completed the course (i.e., alone, with someone else, as farm training). Furthermore, they were asked to rate the course on a 5-point Likert scale (i.e., from 1 to 5,1 being very good and 5 being poor) and rate how much they had learned during the course. Participants could also state whether the course convinced them to perform the task more accurately and whether they felt more confident in conducting the task. In addition, we asked the participants whether the SOP was feasible on their farm and whether such repetitions of knowledge were considered valuable. Two open text fields (i.e., "What was the most important thing you learned in the course?" and "We appreciate your comments and suggestions") allowed participants to provide statements, feedback, and suggestions, which could also be provided via email or WhatsApp text messages.
Learner experiences such as access, page visits, total time spent, completion, and quiz scores were observed with the learning management system (Gomo Learning). Quantitative data were collected with 5-point Likert scales and reported as frequencies and percentages. Qualitative feedback regarding the microlearning courses that was entered into open text fields was summarized and is reported below.

Seventy-nine interested persons were invited to take the first course (tube feeding colostrum), and 49 (62\%) participated. Three farmers contacted the researchers after the first course was launched, leading to 82 invitations being sent out for the second course (bottle feeding colostrum) and the third course (measuring colostrum quality). For all 3 courses combined, 243 invitations were mailed out and 117 participants (48\%) launched the courses.

The courses were cloud based and accessible with web-enabled devices. The majority took the tube feeding $(62 \%)$ and bottle feeding (i.e., $79 \%$ ) courses on a desktop computer, whereas the remaining participants accessed these 2 courses with their smartphones. One person used a tablet computer to launch both courses. The launches for the colostrum quality course showed a converse distribution, as $40 \%$ used a desktop computer and $60 \%$ used a smartphone to launch the course. The number of participants decreased after the first course to $48 \%$ and to $39 \%$ for the second and third courses, respectively. Most participants launched the first, second, and third course once $(69,77$, and $90 \%$, respectively). The remaining 31, 23, and 10\% launched the courses more than once.

The "relevant background information" section was divided into several questions that could be selected at the participant's own discretion by clicking a button that provided important information about the task described. In the first, second, and third courses, 86, 90, and $93 \%$ of participants accessed this part (Table 4). After selecting "relevant background information," most participants selected 2 or more questions (i.e., 83, 77 , and $56 \%$ in the first, second, and third courses, respectively). The SOP represented one part within the course, displaying the necessary materials and the step-by-step instructions on how to perform the task. Almost all participants selected the SOP [92\% (45/49), $90 \%(35 / 39)$, and $96 \%(27 / 28)$ in the first, second, and third courses, respectively].

For all 3 courses, $55 \%$ of the participants completed the embedded survey. Overall, most participants were owner $(26 \%)$, herdsperson $(24 \%)$, or employee $(23 \%)$ on the farm (Table 1). The remaining persons were family members $(15 \%)$, trainees $(6 \%)$, or veterinarians $(6 \%)$. Overall, the majority of participants $(22 / 39,56 \%)$ of 
Table 1. Role (no.; \% in parentheses ${ }^{1}$ ) of 66 participants who completed a 12-item survey embedded in 3 microlearning courses on tube feeding, bottle feeding, and measuring colostrum quality

\begin{tabular}{lcccc}
\hline Participant role & $\begin{array}{c}\text { Tube } \\
\text { feeding }\end{array}$ & $\begin{array}{c}\text { Bottle } \\
\text { feeding }\end{array}$ & $\begin{array}{c}\text { Colostrum } \\
\text { quality }\end{array}$ & $\begin{array}{c}\text { All } 3 \\
\text { combined }\end{array}$ \\
\hline Trainee & $1 / 27(4)$ & $2 / 25(8)$ & $1 / 14(7)$ & $4 / 66(6)$ \\
Employee & $7 / 27(26)$ & $5 / 25(20)$ & $3 / 14(21)$ & $15 / 66(23)$ \\
Family member & $3 / 27(11)$ & $4 / 25(16)$ & $3 / 14(21)$ & $10 / 66(15)$ \\
Herdsperson & $6 / 27(22)$ & $7 / 25(28)$ & $3 / 14(21)$ & $16 / 66(24)$ \\
Owner & $8 / 27(30)$ & $6 / 25(24)$ & $3 / 14(21)$ & $17 / 66(26)$ \\
Veterinarian & $2 / 27(7)$ & $1 / 25(4)$ & $1 / 14(7)$ & $4 / 66(6)$ \\
\hline
\end{tabular}

${ }^{1}$ Due to rounding, percentages do not always add up to exactly $100 \%$.

courses 2 (bottle feeding) and 3 (colostrum quality) had launched the course in their leisure time.

The learning management system allowed us to accurately track the time that the participants spent on the courses. On average (mean $\pm \mathrm{SD}$ ), the participants spent 11:33 $( \pm 6: 21), 11: 14( \pm 6: 17)$, and 10:04 $( \pm 5: 40)$ min:s on the first, second, and third courses, respectively. After course completion, the participants were asked to estimate the time they spent on each course by selecting 1 of 5 items. Estimated time spent on each course was on average (mean \pm SD) 7:20 $( \pm 2: 34)$, 5:01 $( \pm 4: 18)$, and 5:12 $( \pm 5: 17)$ min:s shorter than the actual time spent on the first, second, and third courses, respectively (Table 2).

Participants were asked on a 3-point scale (i.e., absolutely, undecided, not really) whether they were convinced to perform the task more accurately after completion of the course. Eighty-five percent stated that they were absolutely convinced to perform the task more accurately after the first course, whereas 76 and $75 \%$ chose this statement after the second and third courses, respectively. Overall, $80 \%$ were convinced to work more accurately. Furthermore, participants were asked whether they felt more confident in correct task performance after having taken the course. The answers were given on a 3-point scale (i.e., absolutely, undecided, not really) and are summarized in Table 3. Overall, $77 \%$ felt more confident in performing the task correctly. After the second and third courses, 76 and $83 \%$ of participants, respectively, strongly agreed that repetition of such knowledge was worthwhile. This question was added to the survey form after the first course had been created, and answers could be given on a 3-point scale (i.e., strongly agree, undecided, and disagree). Only one person disagreed with this statement after having taken the bottle feeding course (Table 4). Overall, the 3 courses were rated as very good or good by $89 \%$ of the participants.

Labor expenses range from 15 to $30 \%$ of the gross income on a dairy farm (Mugera and Bitsch, 2005). Regular training of farm personnel is essential to increase productivity (Kilpatrick, 2000) and to ensure and maintain up-to-date knowledge and necessary competence of the workers (Liao and Tai, 2006; Román-Muñiz et al., 2007) and seems to be critical for motivating and engaging the workforce (Durst et al., 2018). Employee engagement is well recognized as a key component of employee and business performance (Medlin and Green, 2014). The ability and encouragement to develop employees' skills helps to motivate employees and decrease turnover rate (Heathfield, 2017). On dairy farms, however, proactive and systematic human resource management is a challenge (Stup et al., 2006). Most dairy managers lack sufficient knowledge and know-how to provide their workers with adequate continuing education (Hesse et al., 2017) and do not encourage or value critical input by their employees (Durst et al., 2018).

Table 2. Average $( \pm \mathrm{SD})$ recorded contact times and estimated time spent (no.; $\%$ in parentheses ${ }^{1}$ ) of 62 participants for 3 microlearning courses on tube feeding, bottle feeding, and measuring colostrum quality

\begin{tabular}{lccc}
\hline Item & $\begin{array}{c}\text { Tube } \\
\text { feeding }\end{array}$ & $\begin{array}{c}\text { Bottle } \\
\text { feeding }\end{array}$ & $\begin{array}{c}\text { Colostrum } \\
\text { quality }\end{array}$ \\
\hline $\begin{array}{l}\text { Actual time spent (min:s) } \\
\text { Participant-estimated time }\end{array}$ & $11: 33 \pm 06: 21$ & $11: 14 \pm 06: 17$ & $10: 04 \pm 05: 40$ \\
$\quad<4$ min & $3 / 26(11)$ & $2 / 25(8)$ & $1 / 11(9)$ \\
$4-5$ min & $8 / 26(30)$ & $8 / 25(32)$ & $4 / 11(36)$ \\
$6-8 \mathrm{~min}$ & $6 / 26(22)$ & $4 / 25(16)$ & $4 / 11(36)$ \\
$9-10 \mathrm{~min}$ & $8 / 26(30)$ & $6 / 25(24)$ & $0 / 0(0)$ \\
$>10 \mathrm{~min}$ & $1 / 26(4)$ & $5 / 25(20)$ & $2 / 11(18)$ \\
\hline
\end{tabular}

${ }^{1}$ Due to rounding, percentages do not always add up to exactly $100 \%$. 
Table 3. Frequency distribution (no.; \% in parentheses) of 64 participants who completed a survey embedded in 3 microlearning courses on tube feeding, bottle feeding, and measuring colostrum quality

\begin{tabular}{lcccc}
\hline Answer $^{1}$ & $\begin{array}{c}\text { Tube } \\
\text { feeding }\end{array}$ & $\begin{array}{c}\text { Bottle } \\
\text { feeding }\end{array}$ & $\begin{array}{c}\text { Colostrum } \\
\text { quality }\end{array}$ & $\begin{array}{c}\text { All } 3 \text { courses } \\
\text { combined }\end{array}$ \\
\hline Absolutely & $23 / 27(85)$ & $19 / 25(76)$ & $8 / 12(66)$ & $50 / 64(78)$ \\
Undecided & $2 / 27(7)$ & $5 / 25(20)$ & $2 / 12(17)$ & $9 / 64(14)$ \\
Not really & $1 / 27(4)$ & $1 / 25(4)$ & $2 / 12(17)$ & $4 / 64(6)$ \\
Not answered & $1 / 27(4)$ & $0 / 0(0)$ & $0 / 0(0)$ & $1 / 64(2)$ \\
\hline
\end{tabular}

${ }^{1}$ Participants answered the question "Do you feel more confident to perform the task after taking the course?" on a 3-point scale: absolutely, undecided, and not really.

One prerequisite for participation in our study was either an email address or a smartphone with WhatsApp to receive the URL for the courses. Furthermore, access to the internet (stationary PC) or a data plan using cell phones was required to participate in this study. Interestingly, approximately $10 \%$ of the attendees of the continuing education events were interested but did not own either and could not participate in the study. Rural areas have less internet access than urban areas, and fewer rural residents are online compared with urban residents in both Germany and the United States (FCC, 2016; Statista, 2018a).

Overall, $48 \%$ of the invited personnel accessed the courses. Most enrolled in more than 1 course, and we assume that some participants took the courses in pairs or as a group. Thus, response rate could be somewhat higher. However, $78 \%$ stated that they completed the courses alone. There are multiple reasons for this limited response. First, the farm owners or managers interested in the courses might not have encouraged participation in the microlearning courses among their employees. Second, employers might not have given their employees the opportunity to take the courses during work hours. Furthermore, participation was voluntary, and we did not offer any monetary incentive. Last, insufficient internet coverage at work might have prevented some less intrinsically motivated employees from launching the courses at all.

The courses could be accessed with any web-enabled device and were fully responsive (i.e., pages adapted automatically to different screen sizes and devices). The percentage of smartphone users in Germany var- ies between $88 \%$ (50-64 yr of age) and 97\% (30-49 yr of age; Statista, 2018b). It was therefore surprising that the majority of participants accessed the courses via desktop computer and not via smartphone. Slow or lacking internet coverage, especially in the northern (i.e., rural) regions of Germany, could have been one reason for this observation. The microlearning course "bottle feeding colostrum" was created and launched because some participants in the first course (i.e., "tube feeding colostrum") commented that they do not tube feed colostrum and requested specific training materials to revisit their practices on bottle feeding colostrum. The microlearning approach allowed us to address this knowledge gap in a short period of time. On the other hand, the resulting order of the 3 courses might have affected participation because bottle feeding colostrum is a daily routine conducted on almost every dairy farm, is less complicated than tube feeding, and poses fewer risks of injury for the calf. Some participants probably perceived this topic as needless or boring, which might have affected their interest in further courses. This might explain the decreasing participation in the second and third courses. Measuring colostrum quality is perceived as important by $45 \%$ of the producers in the United States, but only 10\% implemented a protocol on their farm (Pempek et al., 2017). Comparable values are not available for Germany. We speculate that some farmers use colostrometers and might have perceived the course title "measuring colostrum quality" as unappealing and therefore did not launch the third course.

The "relevant background information" section was accessed by almost all participants who launched the

Table 4. Number (\% in parentheses) of participants who navigated through the "relevant background information" section and who selected the "standard operating procedure" section for 3 microlearning courses on tube feeding, bottle feeding, and measuring colostrum quality

\begin{tabular}{lrrr}
\hline Section & $\begin{array}{c}\text { Tube } \\
\text { feeding }\end{array}$ & $\begin{array}{c}\text { Bottle } \\
\text { feeding }\end{array}$ & $\begin{array}{c}\text { Colostrum } \\
\text { quality }\end{array}$ \\
\hline Relevant background information & $42 / 49(86)$ & $35 / 39(90)$ & $27 / 29(93)$ \\
0 or 1 question(s) selected & $7 / 42(17)$ & $8 / 35(23)$ & $12 / 27(44)$ \\
$\geq 2$ questions selected & $35 / 42(83)$ & $27 / 35(77)$ & $15 / 27(56)$ \\
Standard operating procedure & $45 / 49(92)$ & $35 / 39(90)$ & $27 / 28(96)$ \\
\hline
\end{tabular}


courses. Clearly, the participants were interested not only in the SOP but also in relevant knowledge pertaining to the process. This is in line with a recent report describing anecdotal evidence from the field that states that it is important to provide the "why" behind the "how" (Liebenow, 2018). It is argued that successful knowledge transfer leads to workers understanding their work and the importance of following the protocol (Wenz, 2007).

A total of $40(65 \%)$ and $33(53 \%)$ participants responded to the 2 open test fields ("What was the most important thing you learned in the course?" and "We appreciate your comments or suggestions"). Of those, $10(8 \%)$ participants stated that they found the information exceeding the mere steps of the procedure to be very useful (e.g., "Most importantly, the courses explain the details that should be complied with, otherwise one does the task as somebody else told you" and "The additional side information [is] valuable").

In addition, most participants who filled out the survey fully agreed that the repetition of knowledge was worthwhile. This shows the value of regular training and refreshing one's knowledge. Furthermore, it supports the finding of a recent survey that most workers are interested in learning (Durst et al., 2018) and want to know why they have to complete a task in a particular way (Liebenow, 2018).

Almost two-thirds of participants took the courses in their leisure time. Clearly, the participants were eager to gain knowledge and were willing to use their leisure time for their training. The high level of motivation was substantiated by the underestimation of the time spent on the courses. We speculate that this finding is indicative of the participants having fun and a high intrinsic motivation while taking the courses, as has been suggested previously for undergraduate students (Conti, 2001). A positive perception is evidenced by the observation that most participants rated the courses as very good or good. Clearly, the courses were effective at creating a feeling of confidence and accuracy in work performance, as most people were convinced to work more accurately after having taken the courses. The study design, however, does not allow drawing any conclusions about knowledge and skills that participants gained by taking the courses. Causalities and associations between parameters, such as position on the farm and assessment of the courses, could not be calculated due to the limited number of participants and the exclusively descriptive analysis. Further research with a larger number of farms is warranted to determine whether SOP embedded in microlearning courses can affect measurable performance parameters of value for the farms and to study strategies to increase participation rate.

\section{ACKNOWLEDGMENTS}

We gratefully appreciate the cooperation and patience of the farms that allowed us to use their facilities and animals for standard operating procedure creation. Anne Hesse was partially funded by Tiergyn e.V. (Berlin, Germany).

\section{REFERENCES}

Amare, G. 2012. Reviewing the values of a standard operating procedure. Ethiop. J. Health Sci. 22:205-208.

Arcury, T. A., J. M. Estrada, and S. A. Quandt. 2010. Overcoming language and literacy barriers in safety and health training of agricultural workers. J. Agromedicine 15:236-248.

Barkema, H. W., M. A. von Keyserlingk, J. P. Kastelic, T. J. Lam, C. Luby, J. P. Roy, S. J. LeBlanc, G. P. Keefe, and D. F. Kelton. 2015. Invited review: Changes in the dairy industry affecting dairy cattle health and welfare. J. Dairy Sci. 98:7426-7445.

Barragan, A. A., J. D. Workman, S. Bas, K. L. Proudfoot, and G. M. Schuenemann. 2016. Assessment of an application for touchscreen devices to record calving-related events in dairy herds and monitor personnel performance. J. Dairy Sci. 99:5662-5670.

Biagiotti, P. R. 2016. Save protocols from procedural drift. Hoard's Dairyman 161:408.

Conti, R. 2001. Time flies: Investigating the connection between intrinsic motivation and experience of time. J. Pers. 69:1.

De Treville, S., J. Antonakis, and N. M. Edelson. 2005. Can standard operating procedures be motivating? Reconciling process variability issues and behavioural outcomes. Total Qual. Manag. Bus. 16:231-241. https://doi.org/10.1080/14783360500054236.

Durst, P. T., S. J. Moore, C. Ritter, and H. W. Barkema. 2018. Evaluation by employees of employee management on large US dairy farms. J. Dairy Sci. 101:7450-7462.

Edelson, N. M., and C. L. Bennett. 1998. Process Discipline: How to Maximize Profitability and Quality Through Manufacturing Consistency. Quality Resources, New York, NY.

Falkenberg, U., V. Krömker, W. Heuwieser, and C. Fischer-Tenhagen. 2019. Survey on routines in udder health management and therapy of mastitis on German dairy farms. Milk Sci. Int. 72:11-15.

Federal Communications Commission. 2016. 2016 broadband progress report. Accessed Jul. 30, 2018. https://www.fcc.gov/reports -research/reports/broadband-progress-reports/2016-broadband -progress-report.

Gassler, G., T. Hug, and C. Glahn. 2004. Integrated Micro LearningAn Outline of the Basic Method and First Results. ARC Seibersdorf Research GmbH, Research Studios Austria, Studio eLearning Environments, Innsbruck, Germany.

Heathfield, S. M. 2017. What is human resource development (HRD)? Accessed Jun. 29, 2018. https://www.thebalancecareers.com/what -is-human-resource-development-hrd-1918142.

Hesse, A., S. Bertulat, and W. Heuwieser. 2017. Survey of work processes on German dairy farms. J. Dairy Sci. 100:6583-6591.

Johnson, P. J., P. A. Oltenacu, and R. W. Blake. 1992. Learnrepro: A computer-assisted training program for teaching dairy reproductive management. J. Dairy Sci. 75:2288-2293.

Kilpatrick, S. 2000. Education and training: Impacts on farm management practice. J. Agric. Educ. Ext. 7:105-116. https://doi.org/10 $.1080 / 13892240008438811$.

Liao, W., and W. Tai. 2006. Organizational justice, motivation to learn and training outcomes. Soc. Behav. Personal. 34:545-556.

Liebenow, A. 2018. Extend the welcome mat with employee training. Accessed Apr. 24, 2018. https://hoards.com/print-article-22961 -permanent.html.

Medlin, B., and K. W. Green Jr. 2014. Impact of management basics on employee engagement. Academy Strategic Manag. J. 13:21-35.

Mohammed, G. S., K. Wakil, and S. S. Nawroly. 2018. The effectiveness of microlearning to improve students' learning ability. Int. J. Educ. Res. Rev. 3:32-38. 
Moore, D. A., W. M. Sischo, S. Kurtz, J. D. Siler, R. V. Pereira, L. D. Warnick, and M. A. Davis. 2016. Improving dairy organizational communication from the veterinarian's perspective: Results of a continuing veterinary medical education pilot program. J. Vet. Med. Educ. 43:33-40.

Mugera, A. W., and V. Bitsch. 2005. Managing labor on dairy farms: A resource-based perspective with evidence from case studies. Int. Food Agribus. Manag. Rev. 8:79-98.

Pempek, J. A., G. M. Schuenemann, E. Holder, and G. G. Habing. 2017. Dairy calf management - A comparison of practices and producer attitudes among conventional and organic herds. J. Dairy Sci. 100:8310-8321.

Reynolds, S. J. 2013. Managing worker safety, productivity, and regulatory issues. Pages 46-57 in Proc. Western Dairy Management Conference, Reno, NV. http://wdmc.org/2013/Managing\%20 Worker\%20Safety, \%20Productivity,\%20and\%20Regulatory \%20 Issues.pdf.

Román-Muñiz, I. N., D. C. Van Metre, and F. B. Garry. 2007. Dairy worker training experiences. Pages 38-40 in Proc. Ann. Conf. American Association of Bovine Practitioners, Vancouver, BC, Canada. https://www.researchgate.net/profile/Ivette _Roman-Muniz/publication/267388217_Dairy_Worker_Training _Experiences/links/552671470cf2628d5afdf684/Dairy-Worker -Training-Experiences.pdf.

Statista. 2018a. Anteil der Internetnutzer in Deutschland in den Jahren 2001 bis 2017. Accessed Jul. 20, 2018. https://de.statista .com/statistik/daten/studie/13070/umfrage/entwicklung-der -internetnutzung-in-deutschland-seit-2001/.
Statista. 2018b. Anteil der Smartphone-Nutzer in Deutschland nach Altersgruppe im Jahr 2017. Accessed Jul. 10, 2018. https://de .statista.com/statistik/daten/studie/459963/umfrage/anteil-der -smartphone-nutzer-in-deutschland-nach-altersgruppe/.

Stup, R. E., J. Hyde, and L. A. Holden. 2006. Relationships between selected human resource management practices and dairy farm performance. J. Dairy Sci. 89:1116-1120.

Ton, Z., and R. S. Huckman. 2008. Managing the impact of employee turnover on performance: The role of process conformance. Organ. Sci. 19:56-68. https://doi.org/10.1287/orsc.1070.0294.

Treville, S., J. Antonakis, and N. Edelson. 2005. Can standard operating procedures be motivating? Reconciling process variability issues and behavioural outcomes. Total Qual. Manage. 16:231-241.

USDA Economic Research Service. 2018. Milk cost of production estimates. Milk cost of production by size of operation. Accessed Jun. 12, 2018. https://usda.library.cornell.edu/concern/publications/ h989r321c?locale $=$ en\&page $=2 \#$ release-items.

Wenz, J. R. 2007. Is your worker training effective? Ask the cows and reduce protocol drift. Page 40 in Proc. Ann. Conf. American Association of Bovine Practitioners, Vancouver, BC, Canada. https://pdfs .semanticscholar.org/4c67/49091e38fea8621a07b1eba52fffda34f219 .pdf.

Winder, C. B., S. J. LeBlanc, D. B. Haley, K. D. Lissemore, M. A. Godkin, and T. F. Duffield. 2018. Comparison of online, hands-on, and a combined approach for teaching cautery disbudding technique to dairy producers. J. Dairy Sci. 101:840-849. 